\title{
A FRAMEWORK OF A SHIP DOMAIN-BASED NEAR-MISS DETECTION METHOD USING MAMDANI NEURO-FUZZY CLASSIFICATION
}

\author{
Rafał Szłapczyński \\ Tacjana Niksa-Rynkiewicz \\ Gdańsk University of Technology, Poland
}

\begin{abstract}
Safety analysis of navigation over a given area may cover application of various risk measures for ship collisions. One of them is percentage of the so called near-miss situations (potential collision situations). In this article a method of automatic detection of such situations based on the data from Automatic Identification System (AIS), is proposed. The method utilizes input parameters such as: collision risk measure based on ship's domain concept, relative speed between ships as well as their course difference. For classification of ships encounters, there is used a neuro-fuzzy network which estimates a degree of collision hazard on the basis of a set of rules. The worked out method makes it possibile to apply an arbitrary ship's domain as well as to learn the classifier on the basis of opinions of experts interpreting the data from the AIS.
\end{abstract}

Keywords: near-miss, collision risk, ship domain, fuzzy classification

\section{INTRODUCTION}

Real number of collisions between ships (especially the collisions in the true sense of this word, i.e. a crash) is so low in many sea regions that safety analysis of navigation over a given water area or fairway [5] requires introducing additional measures. One of them is a percentage of ships passing in so close distance that it may be considered dangerous - the so called near-miss situtation. Such situations are usually detected on the basis of the data from the Automatic Identification System for ships. Many works dealing with the methods for detection of such situations, differring mainly in choosing a set of input parameters as well as a way of subsequent processing the data, have been made so far. A common element of most of them is the application of the so called ship's domain $[6,7,19]$, i.e. an area surrounding a given ship, which should not be violated by other ships.

In this article there is proposed a novel method for detecting near-miss situations on the basis of the data from the AIS.
The method in question makes use of three input parameters. The crucial parameter is a collision risk measure based on ship's domain concept. The supplementing parameters are: relative speed between ships as well as difference in their courses. For classification of ships encounters a neuro-fuzzy network which estimates a degree of collision hazard by using a set of fuzzy rules, was here applied. The proposed method is characteristic of a high flexibility as it makes it possible to employ an arbitrary ship's domain as well as to learn the classifier on the basis of opinions of experts interpreting the data from the AIS. The possible modifications of the method cover also either a change or expansion of the set of input parameters. In such situation it would be necessary only to overwrite the existing rules by new ones without introducing any change into the main structure of the system.

In the subsequent sections of this paper there are presented existing methods for detection near-miss situations as well as the proposed methods: choice of its input parameters, structure of the neuro-fuzzy classifier as well as the conducted analysis of the method's performance. 


\section{EXISTING METHODS FOR DETECTING THE SO CALLED NAVIGATIONAL CONFLICTS AND NEAR-MISS SITUATIONS}

Investigations on detection of near-miss situations are carried out for various sea water areas. In the publication [22] its authors made use of data from the AIS intended for the analyzing of ship traffic in coastal waters of Southeast Texas, Sabine-Neches Waterway (SNWW), important for oil transportation. It is assummed that collision risk is tightly associated with number of the so called conflicts and this number has been tested by examining violations of circular or eliptical ship's domains as well as relative speeds between ships. Similar investigations were performed for the North Sea and recorded in [21]. The navigational conflict was there defined as a potential future violation of ship's domain within a given time horizon. And, the near-miss situation was defined as a real violation of ship's domain to a degree greater than $50 \%$. For detecting both the conflicts and near-miss situations an eliptical domain was used without applying any additional parameters. The investigations presented in [7] were also based on the data taken from the AIS, concerning encounters of ships sailing over the North Sea. The ship's domain was there determined empirically: experiments confirmed its eliptical form for main types of ships encounter situations, especially for overtaking as well as head-on encounters. Next, the obtained ship's domains were used for determining near-miss situations while, apart from ship's domain violations, the classical parameters such as the Distance at the Closest Point of Approach (DCPA ) as well as of the Time to the Closest Point of Approach (TCPA ) were additionally taken into account. A more advanced method for detecting near-miss situations was presented in [24]. The criterion for ship's domain violation was there supplemented with a series of other decision variables, a. o.: the Minimum Distance to Collision (MDTC), DCPA, TCPA, distance to ship's domain, relative speed between ships as well as the Bow Crossing Range (BCR). The worked out method served then for analyzing near-miss situations over the northern part of the Baltic Sea.

All the above specified methods are characteristic of a relatively inflexible approach as far as choice of input parameters, formulation of criteria or decision rules as well as a form of results is concerned.

In opinion of these authors it is justified to develop a more flexible and versatile method. Application of a risk measure based on ship's domain makes it possible to account for specificity of a local ships traffic by means of a domain prepared for a given sea area. And, the basing of the system on a neuro-fuzzy classifier allows to feed back both a detailed information on collision danger and a degree of certainty or uncertainty of such assessment. Therefore, both the above mentioned elements constitute the basis for the proposed novel method.

\section{CHOICE OF INPUT PARAMETERS FOR THE PROPOSED NOVEL METHOD}

These authors decided to choose three, crucial in ther opinion, parameters - decision variables - describing a degree of collision danger. The first variable is the Degree of Domain Violation (DDV). The DDV is a number from the interval $<0,1>$,where 0 stands for lack of domain violation, and 1 - coincidence of mass centres of both ships.

The parameter allows to use an arbitrary model of ship's domain (especially unsymmetrical ones) as well as an arbitrary parametrization of such model.

As a result, it can replace a few earlier applied parameters such as: DCPA, BCR and bearing.

The second selected variable is the relative velocity between two ships $\mathrm{V}_{\mathrm{r}}$ - most of the authors is in agreement as to its influence on degree of collision danger $[22,24]$. The third selected variable is the difference between directions of motion of two ships, $\alpha$, calculated by means of the relations (1):

$$
\begin{aligned}
& \varphi=\left|\varphi_{1}-\varphi_{2}\right|, \\
& \gamma=360^{\circ}-\varphi, \\
& \alpha=\min \left(\min (\varphi, \gamma), 180^{\circ}-\min (\varphi, \gamma)\right)
\end{aligned}
$$

where:

$\varphi_{1}, \varphi_{2}-$ courses of two ships,

$\varphi$ - difference in courses of two ships,

$\gamma$ - complementary angle for $\varphi$ up to $360^{\circ}$, $\min (\varphi, \gamma)$ - the smaller value out of .

Consequently, the variable a takes values from the interval $<0^{\circ}, 90^{\circ}>$ :

- $0^{\circ}$ - for parallel courses (identical or opposite ones),

- $90^{\circ}$ - for mutually perpendicular courses,

- intermediate values - for other combinations of courses.

It was assumed, that at constant relative speed between ships collision probability is lowest for parallel courses (overtaking and head-on encounters), whereas it is greatest for perpendicular courses (crossing encounters) because mutual situation of ships is more difficult to predict as well as it is necessary to make a greater maneouvre to avoid collision. Values of all the three selected variables can be determined for every ships encounter by automatic processing the data available from the AIS: lengths of ships and their instantaneous positions and courses. For simulation purposes the data available from the portal www.marinetraffic.com, were utilized in this work.

\section{GENERAL STRUCTURE OF THE SYSTEM}

The neuro-fuzzy systems constitute a synthesis of concepts of neural networks and fuzzy systems $[2,14,15]$. A characteristic feature of such classifiers is an incorporation 
of experts knowledge directly into their structures. Among the family of neuro-fuzzy systems the three groups can be distiguished: Mamdani systems, logic systems and TakagiSugeno ones. For classification tasks, Mamdani systems are usually applied. Their effectiveness was confirmed many times $[1,13,14,23]$. Into the system is introduced the knowledge which is defined as initial, basic or expert one. It is represented by means of fuzzy rules which make it possible to interpret it appropriately at any instance, which is not possible in case of application of systems based only on neural networks [13].

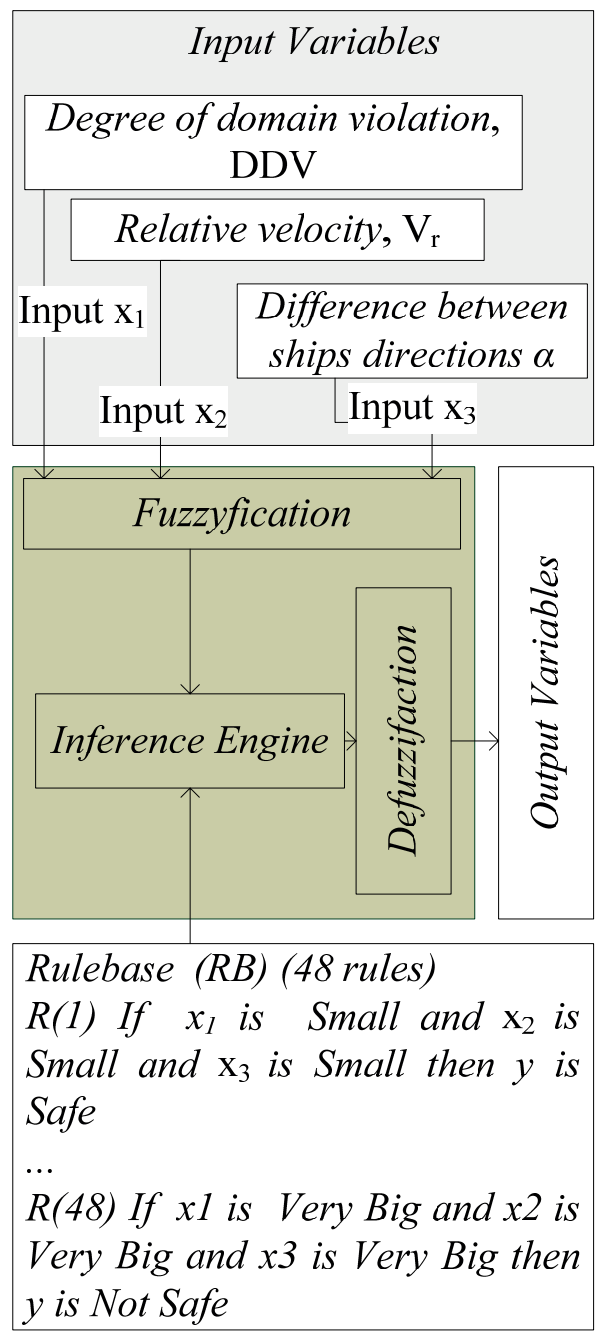

Fig. 1. Architecture of the system for classification based on Mamdani model

Hence, in this work it is proposed to develop a neurofuzzy system, to base its architecture on Mamdani model, as wel as to make use of an input data space and a set of fuzzy rules determined in advance. Additionally, the application of such solution allows to extend the system in the future and use it for interpretation and classification of the knowledge dynamically gained from the AIS. The general schematic diagram of the system is shown in Fig. 1.

The distinguished fragment of the classifier (Fig. 1) is built of the following elements: "Fuzzyfication", "Inference Engine"and "Defuzzyfication". The "Fuzzyfication" is responsible for fuzzifying process and allows to present input data in the domain of fuzzy sets. The values appropriately activate the rules which have been declared in advance and placed into the block „Rulebase (RB)”. The set of the RB rules is usually called the base of rules or linguistic model $[3,23]$. A degree of activation of the rules affects final classification result achieved as a result of defuzzyfication process carried out in the block "Defuzzyfication".

In the worked out system there is assumed that it contains $N$ fuzzy rules where a number of the particular rule $R^{(r)}$ is identified by the variable $r$ so that $r=1, \ldots, N$.

Inputs to the system are numbered beginning from 1 up to $n$, while subsequent input variables of the linguistic model are denoted as follows: $x_{1}, x_{2}, \ldots, x_{n}$.

The space of input variables is denoted in the form of $X_{i}$, $i=1, . ., n$, and the space of output variables $-Y_{j}$, where $j=1, \ldots, m$. Fuzzy sets are defined in the domain of real numbers and denoted respecting the inputs and outputs according to the relation (2):

$$
A_{i}^{r} \subseteq X_{i} \subset R, B_{j}^{r} \subseteq Y_{i} \subset R
$$

Form of fuzzy rules is determined in compliance with the formula given in [2], i.e.:

$$
\begin{array}{r}
R^{(r)} \text { : If } x_{1} \text { is } A_{1}^{r} \text { and ... and } x_{n} \text { is } A_{n}^{r} \\
\text { then } y_{1} \text { is } B_{1}^{r} \text { and ... and } y_{m} \text { is } B_{m}^{r}
\end{array}
$$

\section{ARCHITECTURE OF THE WORKED OUT SYSTEM}

In this paper, an emphasis is put on utilization of the basic knowledge in its unchanged form. Initially, the defined rules were implemented directly together with some fuzzy sets. The basic knowledge comprises 48 fuzzy rules defined in the space of three input variables: $D D V, V_{r}, \alpha$, which are attributed to the signals $x_{1}, x_{2}, x_{3}$, respectively. The system has one output only; hence: $\mathrm{n}=3, \mathrm{~N}=48, \mathrm{~m}=1$.

For purposes of better matching up the system to experts knowledge the fuzzy sets were described not only by means of Gauss function. The membership functions (MFs) may have a sigmoidal or triangular, $f_{\text {tri }}$ or trapezoidal, $f_{\text {trap }}$, form as well as $f_{s}$ and $f_{z}$, i.e. spline-based functions also called Zadeh's S-function [4]

$$
f_{\text {tri }}(x, a, b, c)=\left\{\begin{array}{c}
0 \text { dla } x \leq a \\
\frac{x-a}{b-a} \text { dla } a<x \leq b \\
\frac{c-x}{c-b} \text { dla } b<x \leq c \\
0 \text { dla } x>c
\end{array}\right.
$$




$$
f_{\text {trap }}(x, a, b, c, d)=\left\{\begin{array}{c}
0 \text { dla } x \leq a \\
\frac{x-a}{b-a} \text { dla } a<x \leq b \\
1 \text { dla } b<x \leq c \\
\frac{d-x}{d-c} \text { dla } c<x \leq d \\
0 \text { dla } x>c
\end{array}\right.
$$

The parameters a, b, c, d (Param. MFs) characterize particular fuzzy sets according to the relations $(3,4)$. Their applied values are given in Tab.1 through Tab. 4.

Tab. 1. Collection of characteristic values of the fuzzy sets $A_{1}$ described
in the space of the variable $x_{1}(D D V)$

\begin{tabular}{|c|c|c|c|}
\hline Linguistic variable & Name & MFs & Param. MFs \\
\hline Zero & Z & $f_{t r i}$ & {$\left[\begin{array}{lll}0 & 0 & 0\end{array}\right]$} \\
\hline Small & S & $f_{\text {trap }}$ & {$\left[\begin{array}{llll}0 & 0 & 0.1 & 0.3\end{array}\right]$} \\
\hline Medium & MID & $f_{t r i}$ & {$\left[\begin{array}{lll}0.2 & 0.3 & 0.4\end{array}\right]$} \\
\hline Big & BIG & $f_{t r i}$ & {$\left[\begin{array}{lll}0.3 & 0.4 & 0.5\end{array}\right]$} \\
\hline Very Big & VB & $f_{\text {trap }}$ & {$\left[\begin{array}{lllll}0.4 & 0.6 & 1 & 1\end{array}\right]$} \\
\hline
\end{tabular}

Tab. 2. Collection of characteristic values of the fuzzy sets $A_{2}$ described in the space of the variable $x_{2}\left(V_{r}\right)$

\begin{tabular}{|c|c|c|c|}
\hline Linguistic variable & Name & MFs & Param. MFs \\
\hline Small & $\mathrm{S}$ & $f_{\text {trap }}$ & {$\left[\begin{array}{llll}0 & 0 & 5 & 10\end{array}\right]$} \\
\hline Medium & MID & $f_{t r i}$ & {$\left[\begin{array}{lll}5 & 10 & 20\end{array}\right]$} \\
\hline Big & BIG & $f_{t r i}$ & {$\left[\begin{array}{lll}10 & 20 & 30\end{array}\right]$} \\
\hline Very Big & VB & $f_{\text {trap }}$ & {$\left[\begin{array}{lllll}2 & 0 & 30 & 60 & 60\end{array}\right]$} \\
\hline
\end{tabular}

Tab. 3. Collection of characteristic values of the fuzzy sets $A_{3}$ described in the space of the variable $x_{3}(\alpha)$

\begin{tabular}{|c|c|c|c|}
\hline Linguistic variable & Name & MFs & Param. MFs \\
\hline Small & S & $f_{\text {trap }}$ & {$\left[\begin{array}{llll}0 & 0 & 15 & 30\end{array}\right]$} \\
\hline Medium & MID & $f_{\text {tri }}$ & {$\left[\begin{array}{lll}15 & 30 & 45\end{array}\right]$} \\
\hline Big & BIG & $f_{\text {tri }}$ & {$\left[\begin{array}{lll}30 & 50 & 70\end{array}\right]$} \\
\hline Very Big & VB & $f_{\text {trap }}$ & {$\left[\begin{array}{llll}50 & 70 & 90 & 90\end{array}\right]$} \\
\hline
\end{tabular}

Tab. 4. Collection of characteristic values of the fuzzy sets B described in the space of the output signal $y$

\begin{tabular}{|c|c|c|c|}
\hline Linguistic variable & Name & MFs & Param. MFs \\
\hline Very Safe & VS & $f_{\text {tri }}$ & {$\left[\begin{array}{lll}0 & 0 & 0\end{array}\right]$} \\
\hline Safe & MID & $f_{z}$ & {$\left[\begin{array}{ll}0 & 0.8\end{array}\right]$} \\
\hline Not Safe & BIG & $f_{s}$ & {$\left[\begin{array}{lll}0.2 & 1\end{array}\right]$} \\
\hline Dangerous & D & $f_{s}$ & {$\left[\begin{array}{ll}1 & 1\end{array}\right]$} \\
\hline
\end{tabular}

The produced fuzzy sets are presented in Fig. 2 through Fig. 5.

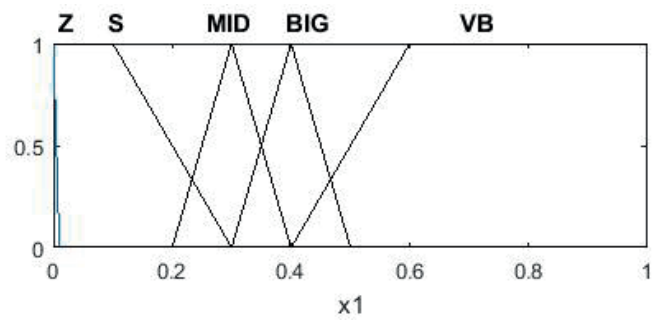

Fig. 2. Diagram of the fuzzy sets $A_{1}$ described in the space of the variable $x_{1}(D D V)$

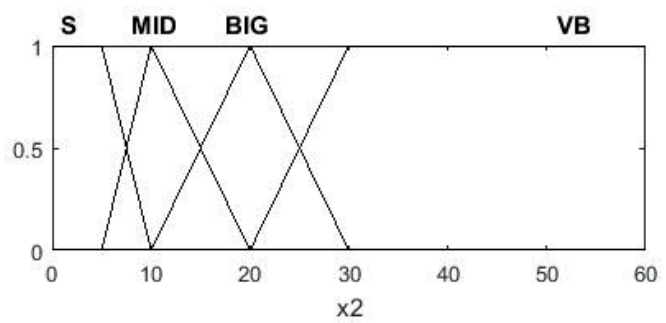

Fig. 3. Diagram of the fuzzy sets $A_{2}$ described in the space of the variable $x_{2}\left(V_{r}\right)$

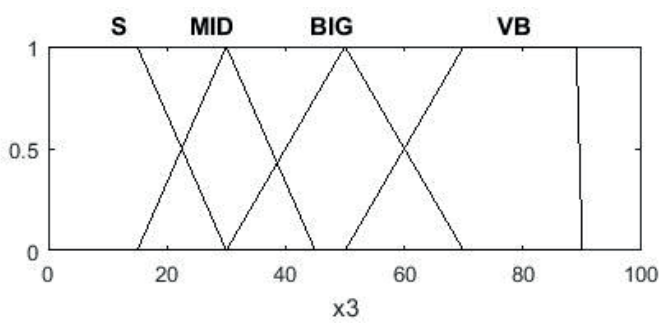

Fig. 4. Diagram of the fuzzy sets $A_{3}$ described in the space of the variable $x_{3}(\alpha)$

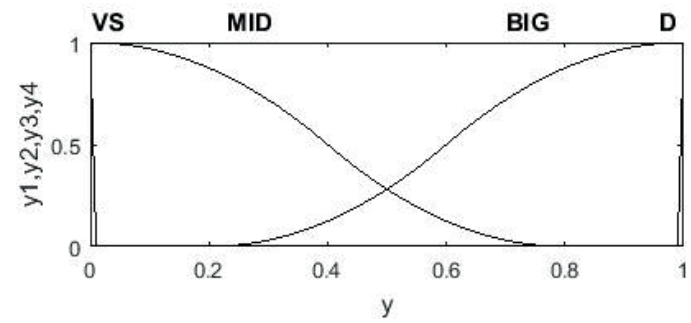

Fig. 5. Diagram of the fuzzy sets B described in the space of the output signal $y$

The general network structure of the proposed system is presented in Fig. 6.

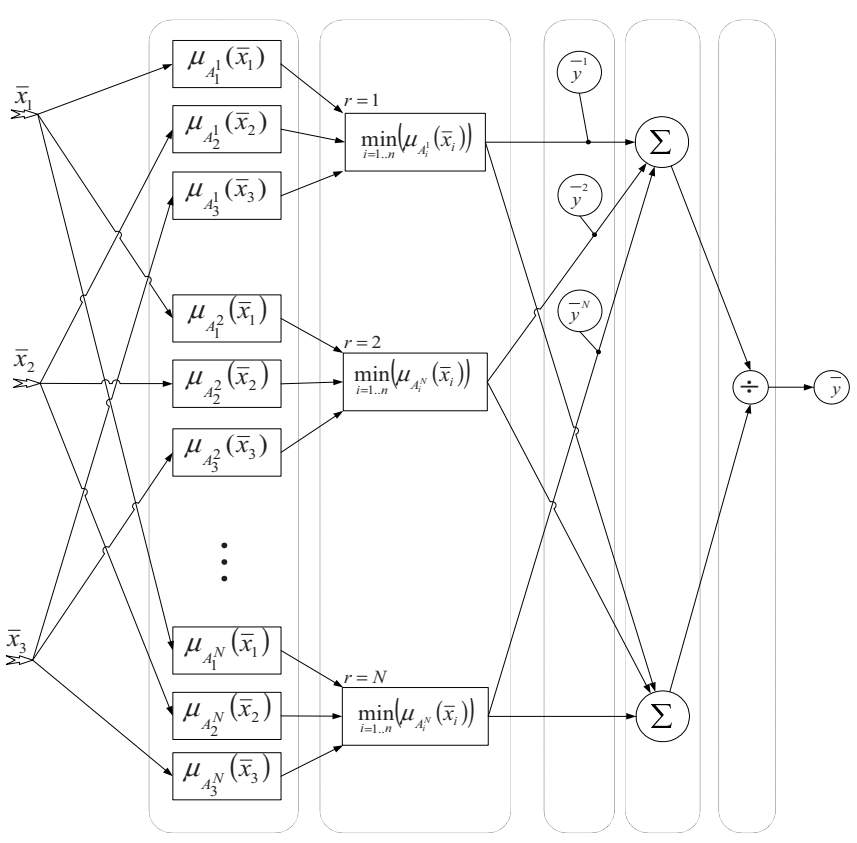

Fig. 6. Model of the general network structure of the neuro-fuzzy system using Mamdani inference method. 
Signals introduced to inputs of the system are read from the space of fuzzy sets.

A value obtained this way is expressed in the form of the membership degree $\mu_{A_{i}^{r}}\left(\bar{x}_{i}\right)$. Basing the system's architecture on the classical neuro-fuzzy model of Mamdani $[2,6,8,15]$, one is able to use the minimum inference rule (5):

$$
\mu_{R^{r}}\left(\mu_{A_{i}^{r}}\left(\bar{x}_{i}\right)\right)=\min _{i=1 . . n} \mu_{A_{i}^{r}}\left(\bar{x}_{i}\right)
$$

In such case the output signal of the system is expressed by the relation (6). This operation is executed by the block "Deffuzzyfication" (Fig. 1).

$$
\bar{y}=\frac{\sum_{r=1}^{N} \bar{y}^{r} \min _{i=1 . . n} \mu_{A_{i}^{r}\left(\bar{x}_{i}\right)}}{\sum_{r=1}^{N} \min _{i=1 . . n} \mu_{A_{i}^{r}}\left(\bar{x}_{i}\right)}
$$

The designed system generates a response on whether a given situation has been more or less safe. A degree of the assesment is dependent on a value obtained from the output 1 - the closer this value to 1 the more dangerous the situation.

\section{SIMULATION TESTS AND EXAMPLE RESULTS OF OPERATION OF THE SYSTEM}

The proposed system serves as a classifier. It was initiated together with experts knowledge as well as tested with the use of real data. The observed results are presented below.

\section{INITIALIZATION OF THE SYSTEM}

The worked out neuro-fuzzy system makes use of the set of 48 basic rules. They determine the space which may be presented on diagrams which illustrate dependence of output signal on particular input signals (Fig. 7 through Fig. 9).

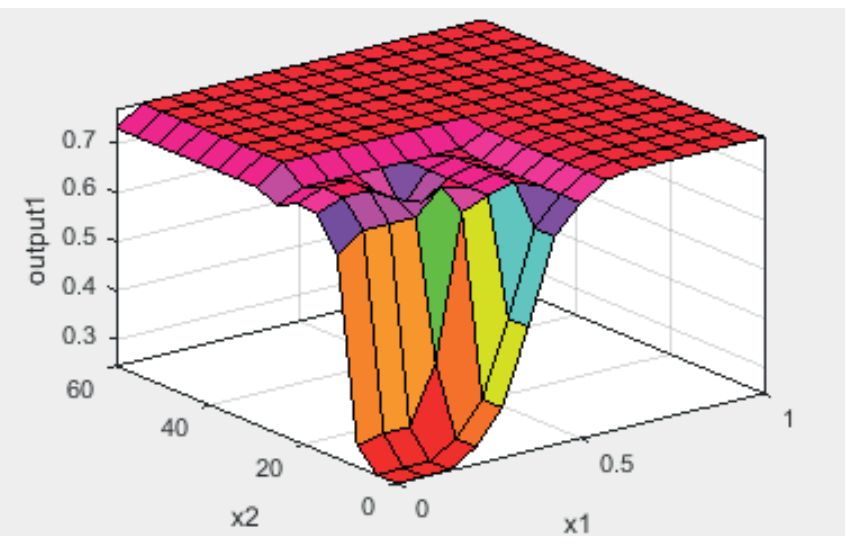

Fig. 7. Diagram of relation between values of the input variables $x_{1}(D D V)$, $x_{2}\left(V_{r}\right)$ and values of the output signal $y$ from the system

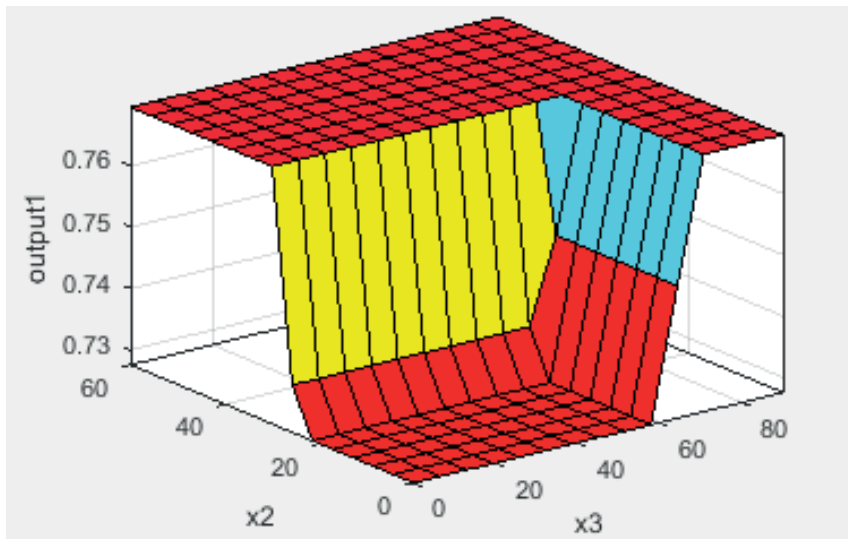

Fig. 8. Diagram of relation between values of the input variables $x_{2}\left(V_{r}\right), x_{3}(\alpha)$ and values of the output signal $y$ from the system

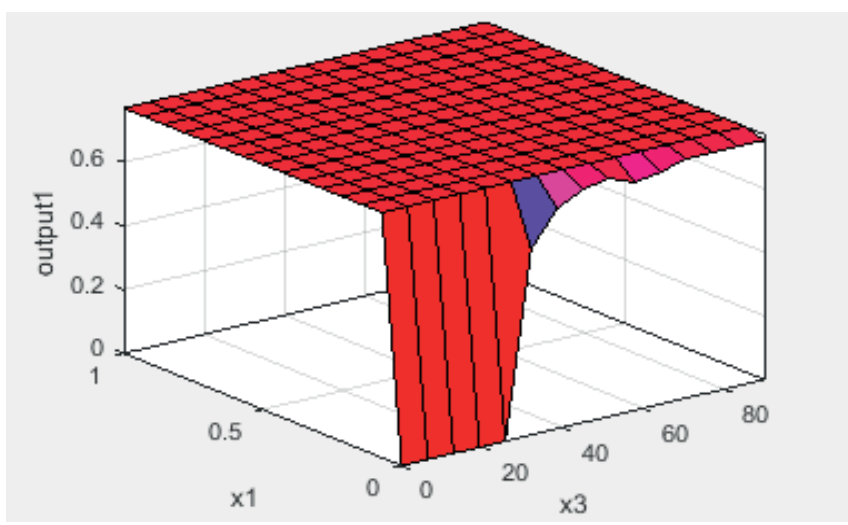

Fig. 9 Diagram of relation between values of the input variables $x_{1}(D D V)$, $x_{3}(\alpha)$ and values of the output signal $y$ from the system

The signal 'outputl' takes values from the interval $\langle 0,1\rangle$, while values more close to 1 indicate a greater probability of collision.

\section{INPUT DATA}

For simulation purposes there was selected a decentralized ellipse whose half-axis lengths as well as longitudinal and transverse shift of the ship relative to centre of the ellipse depend on the ship length $L$ (Fig. 10). This shape is based on the today domains determined experimentally $[6,20]$.

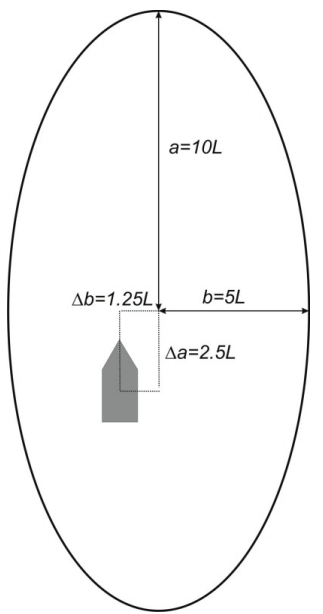

Fig. 10. Decentralized elliptical domain of the ship ( $L-$ ship's length) 
And, as far as the data dealing with ships' encounters are taken into account, the use was made of the data available from the portal www.marinetraffic.com, because no direct access to the data from the AIS has been possible.

A part of the data was generated during direct observation of motions of ships sailing over the Baltic Sea, carried out with the use of the above mentioned portal, (Fig. 11). Selection of the ships under observation was aided by filters available in this portal.

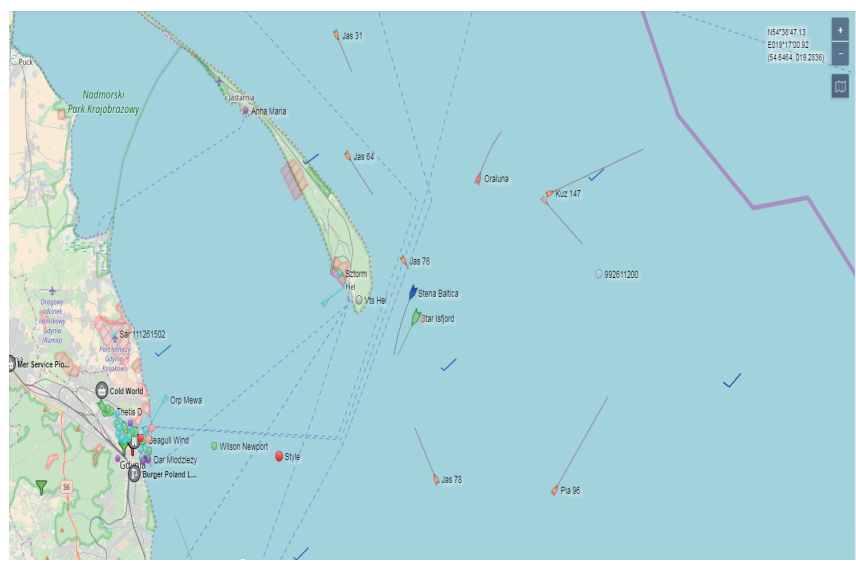

Fig. 11. Screen dump of an example observation taken in the coastal area of Gdynia port on 2017-11-21, 14:50

\section{EXAMPLE RESULTS OF OPERATION OF THE METHOD}

In neuro-fuzzy systems, there are analyzed values obtained after defuzzyfication.

They have sharp quantities from the interval $<0,1>$. The proposed system performs a simple classification. A safe situation is indicated by values $<0.5$, while a hazardous sitution - by values $\geq 0.5$.

The example results are given in Tab. 5 which covers values of the evaluation made by the system for selected sets of input data.

Tab. 5. Collection of example values introduced into inputs to the system together with output information and final evaluation of the situation

\begin{tabular}{|c|c|c|c|c|c|}
\hline Nr. & DDV & Vr & $a$ & $\begin{array}{c}\text { Output } \\
\text { co }\end{array}$ & Verdict \\
\hline 1 & 0,1 & 12 & 10 & 0,39 & Safe \\
\hline 2 & 0,1 & 12 & 32 & 0,44 & Safe \\
\hline 3 & 0,1 & 12 & 52 & 0,49 & Safe \\
\hline 4 & 0,1 & 12 & 72 & 0,53 & Near-miss \\
\hline 5 & 0,1 & 22 & 10 & 0,47 & Safe \\
\hline 6 & 0,1 & 22 & 32 & 0,52 & Near-miss \\
\hline 7 & 0,1 & 22 & 52 & 0,56 & Near-miss \\
\hline 8 & 0,1 & 22 & 72 & 0,61 & Near-miss \\
\hline 9 & 0,1 & 32 & 10 & 0,54 & Near-miss \\
\hline 10 & 0,1 & 32 & 32 & 0,59 & Near-miss \\
\hline 11 & 0,1 & 32 & 52 & 0,64 & Near-miss \\
\hline 12 & 0,1 & 32 & 72 & 0,68 & Near-miss \\
\hline
\end{tabular}

\begin{tabular}{|c|c|c|c|c|c|}
\hline Nr. & DDV & $\mathrm{Vr}$ & $\alpha$ & $\begin{array}{l}\text { Output } \\
\text { co }\end{array}$ & Verdict \\
\hline 13 & 0,25 & 5 & 10 & 0,41 & Safe \\
\hline 14 & 0,25 & 5 & 32 & 0,46 & Safe \\
\hline 15 & 0,25 & 5 & 52 & 0,51 & Near-miss \\
\hline 16 & 0,25 & 5 & 72 & 0,55 & Near-miss \\
\hline 17 & 0,25 & 12 & 10 & 0,47 & Safe \\
\hline 18 & 0,25 & 12 & 32 & 0,51 & Near-miss \\
\hline 19 & 0,25 & 12 & 52 & 0,56 & Near-miss \\
\hline 20 & 0,25 & 12 & 72 & 0,60 & Near-miss \\
\hline 21 & 0,25 & 22 & 10 & 0,54 & Near-miss \\
\hline 22 & 0,25 & 22 & 32 & 0,59 & Near-miss \\
\hline 23 & 0,25 & 22 & 52 & 0,63 & Near-miss \\
\hline 24 & 0,25 & 22 & 72 & 0,68 & Near-miss \\
\hline 25 & 0,25 & 32 & 10 & 0,62 & Near-miss \\
\hline 26 & 0,25 & 32 & 32 & 0,66 & Near-miss \\
\hline 27 & 0,25 & 32 & 52 & 0,71 & Near-miss \\
\hline 28 & 0,25 & 32 & 72 & 0,75 & Near-miss \\
\hline 29 & 0,32 & 5 & 10 & 0,44 & Safe \\
\hline 30 & 0,32 & 5 & 32 & 0,48 & Safe \\
\hline 31 & 0,32 & 5 & 52 & 0,53 & Near-miss \\
\hline 32 & 0,32 & 5 & 72 & 0,57 & Near-miss \\
\hline 33 & 0,32 & 12 & 10 & 0,49 & Safe \\
\hline 34 & 0,32 & 12 & 32 & 0,54 & Near-miss \\
\hline 35 & 0,32 & 12 & 52 & 0,58 & Near-miss \\
\hline 36 & 0,32 & 12 & 72 & 0,63 & Near-miss \\
\hline 37 & 0,42 & 5 & 10 & 0,46 & Safe \\
\hline 38 & 0,42 & 5 & 32 & 0,51 & Near-miss \\
\hline 39 & 0,42 & 5 & 52 & 0,56 & Near-miss \\
\hline 40 & 0,42 & 5 & 72 & 0,60 & Near-miss \\
\hline
\end{tabular}

While analyzing the results presented in Tab. 5 one may observe an impact of all the three variables on final evaluation of the situation of two ships encounter. In compliance with the initial assumptions, the greatest impact has the variable $D D V$ which expresses a degree of violation of the domain, the next are: the relative speed and difference in courses. Worth stressing, that even a significant violation of the domain (value of 0.42 in the row No. 37) does not determine verdict on the situation to be near-miss if only it is accompanied with a low relative speed $(5 \mathrm{kn})$, and the courses are close to parallel (10 deg difference). On the other hand, even a rather small violation of the domain (value of 0.1) leads to classification of the situation to be dangerous at the simultaneous large relative speed $(32 \mathrm{kn}$ in the rows No. 9 through12) or at the courses close to perpendicular (72 deg in the row No. 4). The obtained results correctly reflect the assumed set of estimation criteria. However it's worth stressing that the set is subjective and both the choice of domain dimensions and theshold values for fuzzy rules should be adjusted to a specifity of ship traffic on a given water area and respective expectations of navigators. 


\section{SUMMARY AND DEVELOPMENT PROSPECTS}

In this article there was proposed a novel method for detection of near-miss situations, (i.e such where a collision has not yet happened, but a degree of risk has been much higher than average ). The method makes use of three input parameters: a collision risk measure based on the ship's domain, DDV, relative speed as well as difference in courses of both ships. The parameters are then transformed by means of a neuro-fuzzy classifier which feeds back output information - a collision risk degree for a given encounter of ships.

The proposed system applies initial rules whose set can be updated or extended.

The planned future extension of the system will contain verification of the rules by a team of experts, learning the system as well as its extension with procedures for taking up and processing a large amount of real data from the AIS.

The method for detection of collision hazardous situations, which is implemented in the system, may be also used in the systems for determining anticollision maneouvres $[8,9,10$, $16]$, navigator's decision supporting systems $[12,17,19]$ or in the systems for ship's route planning and monitoring [18]. These authors conduct preliminary research on the above mentioned issues.

\section{BIBLIOGRAPHY}

1. Chai, Y., L. Jia, Z. Zhang: Mamdani Model based Adaptive Neural Fuzzy Inference System and its Application.

2. Cpałka, K.: Design of Interpretable Fuzzy Systems, Springer, 2017.

3. Cpałka, K., L. Rutkowski: On Designing of Flexible NeuroFuzzy Systems for Classification.

4. Driankov, D., H. Hellendoorn, M. Reinfrank: An Introduction to Fuzzy Control, Springer Berlin Heidelberg, 1996.

5. Goerlandt, F., J. Montewka: Maritime transportation risk analysis: Review and analysis in light of some foundational issues, Reliab. Eng. Syst. Saf. 138 (2015), pp. 115-134.

6. Hansen, M.G., T.K. Jensen, F. Ennemark: Empirical Ship Domain based on AIS Data, (2013), pp. 931-940.

7. van Iperen, E.: Classifying ship encounters to monitor traffic safety on the North Sea from AIS data, TransNav - Int. J. Mar. Navig. Saf. Sea Transp. 9 (2015), pp. 53-60.

8. Lazarowska, A.: Multi-criteria ACO-based Algorithm for Ship's Trajectory Planning, TransNav, Int. J. Mar. Navig. Saf. Sea Transp. 11 (2017), pp. 31-36.
9. Lisowski, J.: Game control methods in avoidance of ships collisions, Polish Marit. Res. 19 (2012), pp. 3-10.

10. Lisowski, J., A. Lazarowska: The radar data transmission to computer support system of ship safety, Solid State Phenom. 196 (2013), pp. 95-101.

11. Nowicki, R.K.: Fuzzy decision systems in issues of limited knowledge (in Polish), Akademia Oficyna Wydawnicza EXIT, 2009.

12. Pietrzykowski, Z., P. Wo, P. Borkowski: Decision Support in Collision Situations at Sea, (2017), pp. 447-464.

13. Rutkowska, D.: Neuro-Fuzzy Architectures and Hybrid Learning, Physica-Verlag HD, Heidelberg, 2002.

14. Rutkowska, D., R. Nowicki: Implication-Based NeuroFuzzy Architectures, Int. J. Appl. Math. Comput. Sci. 10 (2000), pp. 675-701.

15. Rutkowski, L., K. Cpalka: Flexible neuro-fuzzy systems, IEEE Trans. Neural Networks. 14 (2003), pp. 554-574.

16. Szlapczynski, R.: A new method of planning collision avoidance manoeuvres for multi-target encounter situations, J. Navig. 61 (2008).

17. Szlapczynski, R., J. Szlapczynska: Customized crossover in evolutionary sets of safe ship trajectories, Int. J. Appl. Math. Comput. Sci. 22 (2012).

18. Szłapczynska, J.: Multi-objective Weather Routing with Customised Criteria and Constraints, J. Navig. 68 (2015), pp. 338-354.

19. Szłapczyński, R., R. Smierzchalski: Supporting navigator’s decisions by visualizing ship collision risk, Polish Marit. Res. 16 (2009).

20. Wang, Y., H. Chin: An Empirically-Calibrated Ship Domain as a Safety Criterion for Navigation in Confined Waters, (2015).

21. Van Westrenen, F., J. Ellerbroek: The Effect of Traffic Complexity on the Development of Near Misses on the North Sea, IEEE Trans. Syst. Man, Cybern. Syst. 47 (2017), pp. 432-440.

22. Wu, X., A.L. Mehta, V.A. Zaloom, B.N. Craig: Analysis of waterway transportation in Southeast Texas waterway based on AIS data, Ocean Eng. 121 (2016), pp. 196-209.

23. Zadeh, L.A.: The Concept of a Linguistic Variable and its Application to Approximate Reasoning-I, (1975), pp. 199-249. 
24. Zhang, W., F. Goerlandt, P. Kujala, Y. Wang: An advanced method for detecting possible near miss ship collisions from AIS data, Ocean Eng. 124 (2016), pp. 141-156.

25. A historical review of evolutionary learning methods for Mamdani-type fuzzy rule-based systems: Designing interpretable genetic fuzzy systems, Int. J. Approx. Reason. 52 (2011) pp. 894-913.

\section{CONTACT WITH THE AUTHORS}

\section{Rafał Szłapczyński}

e-mail:rafal@pg.edu.pl

Tacjana Niksa-Rynkiewicz

e-mail: tacniksa@pg.edu.pl

Gdansk University of Technology

Faculty of Ocean Engineering and Ship Technology

11/12 Narutowicza St.

80 - 233 Gdańsk

Poland 